\title{
ALGUNAS REFLEXIONES SOBRE LA BIOGRAFÍA DIVULGATIVA. LOS CASOS DE MONLAU, RUBIO Y GINÉ*
}

\author{
Ricardo Campos Marín \\ Departamento de Historia de la Ciencia. Instituto de Historia CSIC
}

\section{RESUMEN}

Este trabajo pretende reflexionar, a partir de los casos de Pedro Felipe Monlau, Federico Rubio y Juan Giné y Partagás, sobre las dificultades, tanto formales como de contenido, que entraña la biografía divulgativa. Los problemas de localización de las fuentes, la falta de estudios previos, el difícil equilibrio entre individuo y sociedad, la representatividad de los individuos son algunas de las cuestiones que se abordan en este artículo.

PALABRAS CLAVE: Biografía, divulgación científica, Monlau, Rubio, Giné.

\section{SUMMARY}

The current article aims to study the popular nonscholar and its formal and ground difficulties based in the particular cases of Pedro Felipe Monlau, Federico Rubio and Juan Giné y Partagás. Some of the principal subjets in this work are how to find documents, the scarce of former studies, the difficult balance between people and society and the representative value of biographied people.

KEY WORDS: Biography, scientific popularization, Monlau, Rubio, Giné.

\section{I.}

Existe un amplio acuerdo sobre el hecho de que la biografía es hoy un género en auge en el panorama historiográfico español. Hace, apenas veinte años no gozaba de buena reputación entre la mayoría de historiadores y, tampoco parecía existir una demanda o un interés por parte del público lector ${ }^{1}$. El

* Trabajo realizado en el marco del Programa Ramón y Cajal de Contratación de Doctores del MCyT (Convocatoria 2002) y del proyecto de investigación BHA2003-01664 del MCyT

1 Veiga Alonso, X. R. (1995-1996), «Individuo, Sociedad e Historia. Reflexiones sobre el Retorno de la biografía», Stud. His., $H^{a}$ cont, 13-14, pp. 131-147. 
género biográfico era rechazado por no responder a las inquietudes de las escuelas y tendencias historiográficas más vanguardistas del momento preocupadas en demostrar el carácter científico de la historia y en construir un paradigma en este sentido. El estudio de las estructuras, como argumento explicativo del devenir histórico, primaba frente al individuo, que desaparecía engullido por las fuerzas económicas y sociales ${ }^{2}$.

Sin embargo, la tensión entre biografía e historia no constituye ninguna novedad y perdura desde la antigüedad ${ }^{3}$. No obstante, se acrecienta desde que la historia se constituye en ciencia a partir de la segunda mitad del siglo XIX, y culmina en el XX de la mano de los distintos estructuralismos y postestructuralismos, hasta el punto de convertir a la biografía en un género «moral y científicamente sospechoso. $\rangle^{4}$ Sin embargo, pese a la marginalidad y abierto rechazo del individuo por parte de la historiografía de las décadas de 1960 y 1970, es preciso reconocer también los excesos de la biografía que, con frecuencia dota al sujeto de una excesiva centralidad y unidad, anulando su con-

2 La bibliografía dedicada a la reflexión sobre la biografía ha tenido un notable impulso en los últimos años. A modo de ejemplo puede verse: ALVAREZ JunCO, J. (1990), El emperador del Paralelo: Lerroux y la demagogia populista, Madrid, Alianza Editorial; BuRDIEL, I. (2000), «La Dama de Blanco. Notas sobre la biografía histórica». En BurdiEL, I y PÉREZ Ledesma, M. (Coords), Liberales, agitadores y conspiradores. Biografias heterodoxas del siglo XIX, Madrid, Espasa-Calpe pp. 17-47; LE GofF, J. (1996), Saint Louis, Paris, Gallimard; LE GofF, J. (1985), «Comment écrire une biographie historique aujourd'hui?», Le Débat, 54, pp. 48-53; LEVI, G. (1990), «Les usages de la biographie», Annales ESC, novembre-décembre 1989, nº, pp. 1325-1336; LORIGA, S. (1996), «La biographie comme problème». En: RAVEL, J. (Direction), Jeux d'échelles. La microanalyse à l'expérience» Paris, Hautes Études, Gallimard, Le Seuil, pp. 209-231; MorAles MoyA, A. (1993), «Biografía y narración en la Historiografía actual», en AA.VV. Problemas actuales de la historia. Terceras Jornadas de Estudios Históricos. Salamanca, Ediciones de la Universidad de Salamanca, pp. 229-257; PIQUERAS, J.A. (1994), «De la biografía tradicional a la historia individual, grupal y masiva.» En Carasa Soto, P. (Ed), Elites. Prosopografía Contemporánea. Valladolid, Secretariado de Publicaciones. Universidad de Valladolid, pp. 53-62; VeIGA Alonso, (1995-1996).

3 Una interesante análisis sobre las tensiones entre biografía e historia a lo largo del tiempo, asi como de los intentos durante el siglo XIX por parte de Thomas Carlyle, Jacob Buckhardt e Hyppolyte Taine de presentar proyectos biográficos «fuertes» que dieran al género el relieve del que carecía frente a la nueva historia científica puede verse en LoRIGA, S. (1996), pp. 209-231. Una perspectiva general pero ilustrativa sobre los avatares de la biografía desde la antigüedad hasta la actualidad desde una perspectiva fundamentalmente francesa puede seguirse en CANDAR, G. (2000), «Le statut de la biographie. Essai de chronologie», Correspondances, 61, pp. 11-16. El artículo ha sido consultado en www.irmcmaghreb.org.

4 Burdiel (2000), pp. 21-27. 
textualización histórica. En su versión más radical la biografía se transforma en hagiografía, glorificando al individuo y negándole su historicidad. Ahora bien, la existencia de estas tensiones no significa que no hayan habido intentos de crear «una corriente de aproximación biográfica alternativa que ha sido frecuentemente olvidada tras el tópico de la preeminencia indiscutible de la monumental, positivista e individualista biografía decimonónica» ${ }^{5}$.

Esta tensión es evidente en el campo específico de la historia de la medicina y de la ciencia donde la biografía es una cuestión controvertida debido, entre otras razones, al enorme peso que ha tenido el estudio de las ideas científicas en si mismas, haciendo no sólo desaparecer a los individuos que las elaboraban sino también al contexto social en el que se desarrollaban. Por otra parte, desde la década de 1970, las corrientes más modernas de historia social de la ciencia, al igual que sucedió en el campo de la historiografía general, se centraron en el estudio de las estructuras y de los factores que convergían en el desarrollo científico, dejando de lado las contingencias individuales en dichos procesos.

Pero también es cierto, que los vicios más habituales de la biografía han encontrado en la historia de la ciencia un paraiso para desarrollarse. La conversión del científico en un precursor o avanzado, en definitiva en un héroe solitario e incomprendido, ha sido y todavía sigue siendo una cualidad de muchas biografías sobre científicos, si bien la ponderación y el buen quehacer parece que comienzan a ser la tónica general en este rama de la historiografía ${ }^{6}$. Por otra parte, las biografías colectivas, parecen gozar de mejor acogida entre los historiadores de la ciencia. La prosopografía, que ha dado buenos resultados en el campo de la historiografía general ${ }^{7}$, ha tenido un cierto impulso en la historia de la ciencia del ámbito anglosajón, permitiendo trazar perfiles de comunidades científicas y explicar determinadas tomas de posición ante ciertas teorías ${ }^{8}$.

\footnotetext{
5 Burdiel (2000); LoRiga (1996)

6 A este respecto véanse las sugerentes reflexiones de TATON, R. (1987), «Las biografías científicas y su importancia en la historia de las ciencias». En LAFUENTE, A; SALDAÑA, J.J. (Coordinadores), Historia de las ciencia, Madrid, CSIC, pp. 73-85; HANKINS, T.L. (1979), «In Defence of Biography: The Use of Biography in the History of Science», History of Science, 17 (1), pp. 1-16; también puede verse, aunque su interés sea menor KRAGH, H. (1989), Introducción a la historia de la ciencia, Barcelona, Editorial Crítica, pp. 219-226.

7 Stone. L. (1986), El pasado y el presente, México, Fondo de Cultura Económica, pp. 61-94.

8 Shapin, S; ThackRay, A. (1974), « Prosopography as a research tool in history of science: the British Scientific community 1700-1800», History of science,12(1) pp. 1-28. PYEN-
} 
En cualquier caso el florecimiento actual de la biografía no ha supuesto tanto un puro retorno del género como su revalorización. ${ }^{9}$ Las reflexiones metodológicas y epistemológicas sobre la historiografía en general y la biografía en particular, han producido un cambio entre los historiadores en la manera de entender ésta última al legitimarla científicamente y ganar honorabilidad $^{10}$. Sin embargo, pese a los fructíferos resultados recogidos desde estos postulados, la actual proliferación de biografías entraña el riesgo, según algunos autores, de abandonar la «historia-problema» en favor de un simple retorno a la tradicional biografía «superficial, anecdótica, vulgarmente cronológica, sacrificando a una psicología anticuada, incapaz de mostrar la significación historica general de una vida individual $»^{11}$.

La buena salud de la biografía no se debe exclusivamente a las reflexiones historiográficas y a la crisis de la historia social. Las transformaciones de la sociedad actual en la que los hechos individuales suscitan una inusitada atención no es ajena «al declive social de los colectivos». El auge del individua-

SON, L. (1977), «Who the Guys Were»: Prosopography in the History of Science, History of science 15-(3), pp. 155-188.

9 Mucho se ha discutido sobre los retornos de diversas formas de hacer historia ante la crisis de la historia social. Como muestra puede verse Le GoFf, J. (1995), «Les retours dans l'historiographie française actuelle». En: BARros, C. (Edtor), Historia a Debate: Actas del Congreso Internacional la Historia A Debate celebrado el 7-11 de Julio de 1993 en Santiago de Compostela, Santiago de Compostela: Historia a Debate, vol 2, pp. 157-165. El conocido artículo de L. Stone sobre el resurgimiento de la narrativa ha tenido mucho que ver en la constante utilización y discusión sobre los retornos: STONE, L. (1986), «El resurgimiento de la narrativa: reflexiones acerca de la vieja y nueva historia», en STONE, L. El pasado y el presente México, Fondo de Cultura Económica, pp. 95-120. El artículo fue originariamente publicado en 1979. Interesantes son las reflexiones de VeIGA AlONSO. X.R. (1996), Biografía y conocimiento histórico. El caso del Conde de Pallares, Historia Contemporánea, 13-14, pp. 341-349.

10 Esta es la apuesta de Alvarez Junco cuando afirma: «No defiendo aquí, por tanto, un retorno a la biografía histórica tradicional. La revolución historiográfica de nuestro siglo ha afectado de manera irreversible- y sin duda, beneficiosa- al entendimiento de lo individual, ya imposible de enfocar como fenómeno cerrado en si mismo, explicable sólo a partir de sus propios datos y coordenadas. De ningún modo se pretende aquí reducir al individuo a mero portador, poco menos que automático de estruturas sociales. Pero si parece fuera de toda discusión que el individuo cumple una función dentro de la dinámica social, e incluso que el hecho mismo de que sus contemporáneos confieran al actor o dirigente personal un papel muy relevante es un síntoma de las caracteristicas de la época o del movimiento político en que se halla inserto.» ALVAREZ JunCO. (1990), p. 12. Las reflexiones de BuRdiEL (2000) a este respecto resultan particularmente sugerentes.

11 Le GofF, J. (1989), pp. 49-50. 
lismo neoliberal en economía, en política o en las pautas personales «habría facilitado el marco ideológico idóneo para reintentar la interpretación de los destinos «libremente construidos», de aquellos hombres hechos a sí mismos, imaginados ajenos a todo condicionamiento o a cualquier determinación económica.» ${ }^{12}$. A ello, se sumaría la demanda del público y el hecho de que para los historiadores la biografía "constituye también un medio honorable de retorno al gran público». Público, por otra parte, al que la mayoría de los historiadores que han reflexionado sobre la biografía, consideran hastiado de los trabajos especializados de la historiografía. Pero cabe preguntarse si el tipo de biografía que los historiadores están dispuestos a ofrecer es el que demanda la mayor parte de ese público potencialmente interesado ${ }^{13}$.

El desinterés por la biografía en España no ha sido exclusivo de las últimas décadas. A diferencia de lo sucedido en otros paises europeos durante el siglo XIX, en nuestro país no se acometió la publicación de grandes enciclopedias y diccionarios biográficos de carácter nacional y sectorial. Esta ausencia, ha tenido el efecto de encontrarnos a comienzos del siglo XXI con graves carencias de repertorios biográficos y por tanto, con profundas lagunas en el conocimiento sobre muchas personalidades, que sólo en los últimos años comienzan a colmarse ${ }^{14}$.

12 Piqueras, (1994), p. 54

13 Gómez Urdañez ha señalado a este respecto: «es indudable que asistimos desde hace apenas cinco años a una nueva edad de oro de las biografías, propiciada en parte por una atención historiográfica cada vez menos tímida y alimentada, sin duda, por la garantía del éxito editorial. Ambas circunstancias han logrado provocar una producción en serie de biografías, favoreciendo la confusión entre lo que debe ser una forma más de análisis histórico y la narración anecdótica a la vieja usanza, disfrazada de novedad y blindada ante posibles críticas gracias a la impunidad que desprende la moda.» GómEZ URDAÑEZ, G. (1996), « Salustiano de Olózaga. La necesidad de una biografía histórica», Historia Contemporánea, 13-14, pp. 239249 , p. 240. Ciertamente la presencia de biografías ha sufrido un notable incremento en los catálogos de las editoriales. Un asunto inquietante, no es tanto este fenómeno sino el tipo de biografías que se escriben y la participación de historiadores reconocidos en ellas. Sirva como ejemplo la colección Cara y Cruz de Ediciones B cuya filosofía es tomar personajes de la vida política española del siglo XX y presentar en un solo libro una biografía positiva (la cara) y otra negativa (la cruz), con el supuesto objetivo de que el lector conozca las luces y sombras de ese personaje fundamental de la historia de España. ¿Tiene este tipo de biografías algo que ver con las reflexiones sobre el género? La nómina de colaboradores es variopinta y en ella figuran desde historiadores como Gabriel Jackson, políticos como Santiago Carrillo hasta profesionales de la manipulación como Pio Moa y César Vidal.

14 Las quejas sobre la falta de repertorios biográficos son una constante en la historiografía española, así como las reivindicaciones sobre la necesidad de solucionar dicha carencia. 
Una faceta del genero biográfico que se resiente especialmente de este árido panorama es el de la biografía divulgativa, que por su carácter sintético requiere de la existencia de trabajos biográficos previos que no siempre se han llevado a cabo.

El objeto de las próximas páginas es plantear algunos de los problemas que entraña este subgénero a partir de las biografías de Pedro Felipe Monlau (1808-1871), Federico Rubio (1827-1902) y Juan Giné y Partagás (18361903) que recientemente he realizado para la editorial Nivola ${ }^{15}$.

La aproximación a los tres autores, no ha sido el fruto de profundas investigaciones sobre sus personalidades. Mis conocimientos sobre ellos eran parciales y estaban relacionados con determinados aspectos concretos de sus obras, utiles para mis trabajos de investigación.

No pretendo, pues, llevar a cabo una amplia reflexión sobre los problemas que entraña la biografía - expuestas de manera concienzuda y brillante por otros colegas - sino analizar algunas de las tensiones y dificultades presentes en el trabajo de biografiar a estos tres médicos e intentar conectarlas con las preocupaciones sobre el género.

\footnotetext{
Una breve pero ilustrativa panorámica sobre estas cuestiones puede verse en AGIRREAZKUEnaga Zigorraga; Serrano Abad, S; Urquijo Goitia, J.R; Urquijo Goitia, M. (1993), Diccionario biográfico de los parlamentarios de vasconia (1808-1876), Eusko Legebiltzarra, Vitoria-Gasteiz, pp.13-18. En el terreno concreto de la historia de la ciencia y la medicina contamos con algunas obras que si bien cubren parcialmente la falta de noticias biográficas, en conjunto todavía son insuficientes. Como ejemplo del esfuerzo realizado véase: LÓPEZ Piñero J.M; Glick, Th; Navarro Brotons, V; Portela, E. (1983), Diccionario histórico de la ciencia moderna en España, Barcelona, Península, 2 vols; CALBET I CAMARASA, J.M; Corbellá I CoRBella. (1981-1983), Diccionari biográfic de metges catalans, Barcelona: Rafael Dalmau: Fundació Salvador Vives Casajuana: Seminari Pere Mata, Universitat de Barcelona, 3 vols; CAMARASA. J.M; Roca Rosell A. (Directores) (1995), Ciència i tècnica als Països Catalans: una aproximació biogràfica [als darrers 150 anys Barcelona : Fundació Catalana per la Recerca, 2 vols. En la actualidad la Real Academia de la Historia ha emprendido la tarea de editar un Diccionario Biográfico Español.

15 CAmpos Marín, R. (2003), Monlau, Rubio, Giné. Curar y gobernar. Medicina y liberalismo en la España del siglo XIX, Madrid, Nivola. La colección Novatores de la que mi trabajo forma parte junto a otros 17 , constituye un interesante ejemplo de presentación de biografías divulgativas sobre científicos españoles y contribuye en cierta medida a llenar el vacio que padecemos de este tipo de obras. No obstante, todavía es muy temprano para conocer el impacto que dicha colección está teniendo en el panorama español. Un reciente análisis, centrado exclusivamente en los volúmenes que esta colección lleva dedicados a científicos del siglo XIX y XX puede verse en LOPEZ OCÓN, L. (2004), «Propuestas para repensar los vaivenes de la cultura científica en la España contemporánea», Ayer, 54 (2), pp. 329-346.
} 
Antes de analizar los problemas concretos que suscita la biografía divulgativa es conveniente acotar el terreno de la misma. Entendida como una síntesis de carácter histórico de los conocimientos existentes sobre un individuo que destacó en algún campo de la vida social o que tuvo un protagonismo importante en la sociedad de su tiempo, la biografía divulgativa debe tomar la vida del individuo escogido como hilo conductor para explicar su obra y la época en que ambas se desarrollaron, procurando conectarlas y mostrando en la medida en que sea posible las interacciones entre ellas. Desde un punto de vista formal este tipo de biografía, dirigida a un público variado, con intereses, formaciones y niveles culturales muy distintos, se caracteriza por estar desprovista del aparato erudito habitual de la investigación histórica, (notas explicativas, referencias constantes a las fuentes, discusiones de carácter profesional) y por la adopción de un estilo ameno y directo.

En el caso concreto de Monlau, Rubio y Giné, se ha procurado combinar tres facetas intimamente unidas:

1) Ofrecer una semblanza completa del individuo biografiado que integre su actividad científica con otras facetas de su personalidad, como los compromisos políticos, las redes de sociabilidad en las que se desenvolvía, las influencias de otros pensadores y científicos, sus lecturas, etc. Incluso, hasta donde ha resultado posible e interesante porque podía ofrecer claves para entender algún aspecto, se han introducido elementos de lo que comúnmente se conoce como «vida privada», entendiendo por ésta aquella que no tiene que ver estríctamente con la faceta pública. Todo ello sin olvidar que las realizaciones y aportaciones científicas son las que deben articular la reconstrucción biográfica de cada sujeto.

2) Otra de las cuestiones tomadas en consideración ha sido ofrecer al lector las claves de la ciencia que practicaba el científico biografiado, analizando el estado de la misma, tanto en el plano nacional como en el internacional con el objeto de poder contextualizar, comprender y valorar sus aportaciones.

3) Por último, se ha intentado sumergir a los lectores en el ambiente de la época, debido a la importancia de los factores económicos, políticos, sociales y culturales en el desarrollo de la medicina. En este sentido, se ha considerado irrenunciable insertar a los tres médicos biografiados en su contexto histórico, subrayando las interacciones entre individuo, ciencia y sociedad. 
Ahora bien, el equilibrio entre individuo y contextualización presenta una tensión fundamental entre ambos polos que entraña al menos dos riesgos. Si se cargan las tintas en la doble contextualización - científica y social- del individuo, se corre el peligro de negar la originalidad al sujeto y olvidar que éste tiene que ser el hilo conductor y el motor del relato biográfico, so pena de reducirlo al «mero síntoma del pasado» al que me refería anteriormente. Por otra parte, una excesiva atención al individuo puede relegar el contexto histórico a un simple decorado o trasfondo en el que transcurre la vida del protagonista, convertido inconscientemente en personaje único y excepcional sin que exista una referencia clara para ubicar su real importancia en la sociedad de su tiempo. Sin embargo, esto no significa que exista una oposición individuo-sociedad, pues los individuos no existen más que en una red de relaciones sociales diversas y no preexisten a éstas. De ahí, que sea absolutamente necesario comprender y conocer la sociedad en que vive el individuo, pues es en ella donde se constituye como tal. ${ }^{16}$ La hagiografía es sin duda la deriva más radical del excesivo hincapié en el individuo pero no la única. La abundancia en el mercado de biografías plagadas de datos y anécdotas, plenas de un psicologismo anacrónico, sin objetivos historiográficos claros o con objetivos que poco tienen que ver con la historia ilustran este «olvido» del contexto.

Desde el punto de vista formal la combinación de éstos tres niveles no es sencilla. Una técnica utilizada por algunos autores al abordar una biografía consiste en dedicar algunos capitulos o puntos a la sociedad de su tiempo para posteriormente centrarse en la actividad científica del individuo como si fueran elementos independientes o pudieran tratarse por separado. Esta opción puede resultar cómoda como solución a las dificultades que entraña la redac-

16 Aunque parece existir un acuerdo entre historiadores sobre el equilibrio que debe imperar en la biografía entre el individuo y el contexto o marco histórico, la práctica muestra una cierta disonancia en las inclinaciones particulares. Véanse las agudas reflexiones de BURDIEL (2000). Las posicíones inclinadas hacia la imposibilidad de separar individuo y sociedad, que comparto, son las de Le Goff, (1996), pp. 21-22 y las de Veiga Alonso. X.R. (1996), Biografía y conocimiento histórico. El caso del Conde de Pallares, Historia Contemporánea, 1314, pp. 341-349. Muy recientemente, en un ámbito algo distinto al de la biografía, si bien con importantes conexiones con ésta, como es el de la historia virtual o del análisis contrafáctico Townson ha realizado una encendida defensa del individuo y del libre albedrío frente al determinismo que, atribuye a los historiadores, muy especialmente a los annalistas y marxistas, incluidos los británicos. Sus argumentos, bien construidos y brillantemente expuestos, no dejan de ser artificiosos y parcialmente lúdicos. Towson N. (Dir) (2004), Historia virtual de España (1870-2004). ¿Qué hubiera pasado si? Madrid, Taurus, pp.15-35. Desde la sociología el tema ha sido abordado por BouRdieu, P. (1986), "L'illusion biographique» Actes de la recherche en sciences sociales, 62-63, pp. 69-72. 
ción de una biografía pero resulta enormemente artificiosa y no resuelve metodológicamente los problemas apuntados.

Una cuestión extraordinariamente compleja, por las implicaciones emocionales y a menudo de carácter ideológico que implica, sobre la que se debe tener clara conciencia como historiadores es la identificación, incluso afecto, que de manera inconsciente se puede tomar al biografiado. En el polo contrario, puede darse un fénomeno similar de carácter negativo: el rechazo del individuo estudiado ${ }^{17}$. En el caso de las biografías divulgativas este riesgo aumenta por su carácter sintético que dificulta los matices.

Otra sombra que se cierne sobre el género y que se acentúa en el caso de la divulgación es la tentación de dar un sentido absoluto a todas las manifestaciones y acciones del individuo objeto de la biografía. En el caso de las biografías comentadas esta tensión ha estado presente, máxime cuando se trataba de ofrecer a través de ellos una visión general de la medicina liberal española del siglo XIX. El hilo conductor utilizado como nexo entre las tres biografías ha sido el compromiso que profesaron con la sociedad de su tiempo. Éste se manifestó en su actividad profesional, caracterizada por un afán innovador y reformador que se plasmó en las diversas empresas científicas que emprendieron con el objetivo de modernizar la medicina española. El compromiso científico fue indisoluble del compromiso ideológico y político con el liberalismo y con la construcción del estado liberal que mostraron a lo largo de su vida, hasta el punto de resultar artificioso intentar separar ambas facetas.

Ahora bien, el riesgo implícitamente presente en las biografías de estas características es la presentación de una imagen excesivamente inteligible y unitaria de los individuos. La marcada implementación en el contexto histórico y el propio carácter divulgativo de las biografías, cuyo objetivo es acercar al público a los tres médicos y hacérselos inteligibles, indudablemente ha pesado en este sentido. Este planteamiento lleva también a otra cuestión que subyace en este tipo de biografía: la representatividad de los individuos escogidos. Este aspecto ofrece una doble faceta. De un lado, cabe preguntarse por el interés que pueden suscitar tres médicos absolutamente desconocidos por el público no especializado. No se puede olvidar que ninguno tuvo una relevancia equiparable a la de las grandes figuras de la medicina europea. Su labor se desarrolló en un ambiente poco propicio y sus aportaciones fueron poco originales y nor-

17 En ocasiones, estos peligros que acechan constantemente al biógrafo, se convierten en abierta e impúdica política editorial como el caso ya comentado de la colección Cara y Cruz de la Ediciones B. Como ejemplo véase JaCkson, G; ALBA.V. (2004), Juan Negrin, Ediciones B, Colección Cara y Cruz, Barcelona. 
malmente resultado de reelaboraciones y adaptaciones a la realidad española de ideas producidas en otros paises con unas estructuras científicas más sólidas. Sin embargo, dentro del contexto español del XIX tuvieron un papel importante en la modernización de la medicina que les convierte en representativos de su tiempo y por tanto su estudio es necesario. Entramos así en la segunda lectura de la representatividad. ¿Son Monlau, Rubio y Giné intercambiables con otros médicos? ¿Son simplemente individuos representativos de la medicina del siglo XIX, cuyas biografías ilustran una sociedad, una situación determinada y más allá de este hecho pierden valor? Se vuelve así al difícil equilibrio entre contexto e individuo y al papel de las contingencias individuales en la historia. Por mi parte, considero que éstas tienen importancia e influyen en el devenir histórico, aunque desde luego no lo determinan. La formación de un individuo, su situación económica y social, los destinos profesionales, sus redes de sociabilidad, sus contactos, etc., son asuntos que pueden resultan primordiales para entender determinados descubrimientos o posiciones científicas y comprender mejor el transfondo histórico en que se desarrollan. Sin embargo, la biografía en si misma explica poco y tiende a convertirse en un relato exclusivamente literario, en una acumulación de datos que no ayuda a comprender fenómenos históricos.

La biografía divulgativa por su propia naturaleza posee una cierta ambigüedad respecto a la localización y empleo de las fuentes. Puede ser el fruto de una investigación profunda, en cuyo caso se parte de un sólido conocimiento documental y de la trayectoria vital del individuo escogido. Asimismo por su carácter sintético se presupone que puede basarse en el aprovechamiento de otros acercamientos biográficos anteriores. Sin embargo, en este último caso, la búsqueda de información puede resultar una tarea compleja debido a la ausencia de repertorios biográficos previos que reunan unas mínimas garantías de calidad, asi como a la práctica inexistencia de biografías bien articuladas metodológicamente que, además de proporcionar datos fiables sobre el individuo, contextualicen bien su actividad e interpreten sólidamente su figura.

En el caso particular de los tres médicos biografiados, la información disponible se caracterizaba por su fragmentación, dispersión y escasez. Se contaba con muy pocas biografías profundas y con una panoplia de notas biográficas publicadas en diversos diccionarios, necrológicas y hagiografias, cuyos contenidos se repetían de manera persistente a lo largo del tiempo, terminando por constituir un cúmulo de lugares comúnes de muy díficil contraste do- 
cumental, cuya comprobación hubiera requerido una verdadera labor de investigación que superaba con creces las exigencias editoriales. El resto de los materiales utilizados han sido los trabajos sobre aspectos concretos de la obra y actividad científica de cada autor, asi como de estudios de historia política, donde en ocasiones se aportaban datos sobre el compromiso ideológico de nuestros médicos. Este pobre panorama de inicio, ha supuesto un importante esfuerzo de búsquedas bibliográficas y de interpretación, conexión y síntesis de materiales de muy desigual calidad.

Para abordar la figura de Monlau se contaba como punto de partida con los acercamientos biográficos previos de Calbet Camarasa ${ }^{18}$ y de Mercedes Granjel ${ }^{19}$ que, ofrecían las grandes líneas de su recorrido intelectual y político. No obstante, ambos son ya trabajos antiguos y pese a sus virtudes resultan insuficientes para esclarecer numerosas cuestiones relacionadas con su militancia política y sus actividades profesionales. Por otra parte, para el análisis de los aspectos relacionados con la higiene pública e industrial de la obra de Monlau disponiamos de los trabajos de López Piñero ${ }^{20}$ y Jutglar ${ }^{21}$. El primero de ellos, pese a su carácter excesivamente descriptivo y centrado casi exclusivamente en las distintas ediciones de la Higiene Pública del médico catalán, tiene el mérito de ser un trabajo pionero en la historiografía española y de ofrecer un interesante análisis del impulso que supuso la obra de Monlau para la consideración del higienismo como una disciplina científica en la España de mediados del siglo XIX, superando con creces, pese a los veinte años de separación al estudio de Jutglar.

Así mismo el folleto publicado en 1864 por J. Monlau, hijo de nuestro higienista, relata los méritos científicos de su padre ${ }^{22}$, y es útil para recabar

18 Calbet Camarasa, J.M. (1971), «El pensament de Pere Felip Monlau» en Actes del I Congrés Internacional d'Historia de la Medicina Catalana, Vol. IV, Barcelona, Scientia, pp. 281-304.

19 Granjel, M. (1983), Pedro Felipe Monlau y la Higiene Española del siglo XIX, Salamanca, Universidad de Salamanca.

20 LÓPEZ PIÑERO, J.Ma . (1964), «El testimonio de los médicos españoles del siglo XIX acerca de la sociedad de su tiempo. El proletariado industrial», En J.Ma LÓPEZ PIÑERO, L. García Ballester, P. Faus Sevilla, Medicina y Sociedad en la España del siglo XIX, Madrid, Sociedad de Estudios y Publicaciones, pp. 110-208.

21 Jutglar, A.(1984), Condiciones de vida y trabajo obrero en España a mediados del siglo XIX / Pere Felip Monlau, y Joaquim Salarich; estudio preliminar y notas críticas a cargo de Antoni Jutglar, Barcelona, Anthropos.

22 Monlau Sala. J. (1864), Relación de los estudios, gados, méritos y servicios y obras científicas y literarias del doctor D. Pedro Felipe Monlau, Madrid, Imprenta y esteriotipia de M. Rivadeneyra. 
datos importantes sobre su trayectoria intelectual y profesional facilitando la ordenación cronológica de muchos aspectos de su vida. Los datos recogidos en estos trabajos no son, sin embargo, suficientes para completar su semblanza. Para aclarar varias cuestiones fue necesario rastrear otros trabajos de diversa índole que aportaban datos sobre su actividad política o analizaban algunos aspectos concretos de su trayectoria como higienista ${ }^{23}$. Aún así, cuestiones como su tarea profesional en Barcelona durante la epidemia de cólera de 1834-1836, su exilio en Francia en 1838, el papel jugado en la elaboración de la ley de Sanidad de 1855, sus posiciones en el Consejo de Sanidad, no han sido todavía investigadas en profundidad. En este sentido, queda sin esclarecer satisfactoriamente, pese a las consecuencias posteriores en su trayectoria profesional e ideológica, los motivos de su paso de las filas progresistas a las conservadoras hacia 1846 y su colaboración desde entonces con los gobiernos conservadores.

Las dificultades apuntadas son todavía mayores en el caso de Giné por la carencia no ya de una biografía, sino de una semblanza mínima sobre su figura. El material de partida para afrontar su biografía estaba compuesto por las consabidas e insuficientes notas en diccionarios y enciclopedias, asi como por una cierta proliferación de trabajos historiográficos sobre aspectos concretos de sus diversas actividades científicas y culturales que, en líneas generales y salvo excepciones centradas mayoritariamente en su faceta como psiquiatra, ${ }^{24}$ carecían de rigor metodológico y objetivos claros ${ }^{25}$.

23 Urteaga, L. (1985), «El pensamiento higienista y la ciudad: la obra de P.F. Monlau (1808-1871)», en A. BONET CORREA (Coord), Urbanismo e Historia Urbana en el mundo Hispano, Madrid, Edit. Univ. Complutense, pp. 397-412; Ollé Romeu, J.M. (1994), Les Bullangues de Barcelona durant la primera guerra Carlina, (1835-1837), 2 vols, Barcelona, El Medol. Esta última obra ha sido un excelente auxiliar tanto para seguir la trayectoria política de Monlau en su juventud como para conocer bien el contexto político en que se desarrolló su militancia liberal progresista.

24 REY, A. (1982), «Clásicos de la psiquiatría española: Juan Giné y Partagás», Revista de la Asociación Española de Neuropsiquiatría, 2 (4), 99-109; VILLASANTE, O. (1997a), «El Certamen Frenopático Español y su papel en el proceso de institucionalización de la Psiquiatría». En: La locura y sus instituciones (Actas de las II Jornadas de Historia de la Psiquiatría), Valencia: Diputación de Valencia, pp. 255-265; VILlaSANTE, O. (1997b), «Primer Certamen Frenopático Español (1883): Estructura asistencial y aspectos administrativos», Asclepio, 49 (1), págs, 79-93. HuERTAS, R. (2002), Organizar y persuadir. Estrategias profesionales y retóricas de legitimación de la medicina mental española (1875-1936), Madrid, Frenia, DIEGUEZ, A. (1998), «El problema de la nosografía psiquiátrica en de J. Giné y Partagás», Asclepio 50, pp. 199-222; DiegueZ, A. (1999), «El tratado de frenopatología de Gine y la Restauración». En Romero, I, Casco, J, Fuentenebro, F y Huertas, R. (eds), Cultura y Psiquiatría del 98 en Es- 
Recientemente, Ausin Hervellá, coincidiendo con el centenario de su fallecimiento, ha publicado una biografía sobre Giné26. Lejos de cumplir las expectativas de ser una biografía integrada sobre el médico catalán, la estructura del libro y la falta de una metodología mínima desde el punto de vista historiográfico lo convierten en un mero catálogo de las actividades de Giné expuestas a lo largo de sus casi 400 páginas. La principal y casi única virtud de esta obra es la gran cantidad de datos que aporta al lector, si bien en algunos casos no se indica la documentación en que están apoyados. Más allá de los datos, no hay un análisis sólido de la figura de Giné que lo inserte bien en el contexto de la sociedad y la medicina catalana y española del siglo XIX y que valore en profundidad sus aportaciones. Esta falta de análisis y de clara inserción en su contexto supone que seguimos sin contar con una biografía sólida sobre la figura de Giné.

De muy distinto calado son los obstáculos que se han de sortear para afrontar la figura de Rubio. El exceso de información sobre su persona en todos los ámbitos de su vida, lejos de facilitar la tarea la dificulta, pues se impone un trabajo de elección y jerarquización de la misma, además de añadirse la tentación de caer en la maraña de anécdotas de todo tipo que proliferan sobre su persona.

paña,Madrid, Necodisne, págs. 51-67; DiegueZ, A. (1999b), «Psiquiatría y género: el naciente discurso médico-psiquiátrico en España y el estatuto social de la mujer», Revista de la Asociación Española de Neuropsiquiatría, 19, 637-652; DiEGUEZ, A. (2000), «Sobre los fundamentos cientificos de la primera psiquiatría española. En torno a la obra de Juan Giné», en Angosto, T, Rodriguez Lopez, A y Simon D (coords), Setenta y cinco años de de historia de la psiquiatria, Ourense, AEN, págs, 111-118. Sin alcanzar la calidad de los anteriores trabajos, resultan particularmente interesantes por las fuentes utilizadas y por aclarar algunos aspectos de la relación de Gine con el manicomio de Nova Belen, los articulos: AUSIN I HeRveLLA, J.L. (1997) «Fundació i primera etapa de la Nova Betlem, 1857-1865», Gimbernat 28, pp. 115-129. Ausin i Hervella, J.L. (1997) «L' época de la direcció de Massó LLorens a la Nova Betlem de Gràcia», Gimbernat, 28, pp. 131-141.

25 Este tipo de trabajos, pese a sus carencias metodológicas, tienen a su favor la aportación de datos que pueden facilitar el futuro abordaje de una biografía sobre Giné, En esta línea estarían los trabajos pioneros recopilados en el libro de DoMEnCEH, E; Corbella, PARellaDA, D. (1987) Bases historicas de la psiquiatría catalana moderna, Barcelona, PPU. También SAncho de SAn Roman, R., (1960), La obra psiquiatrica de Giné y Partagás, Salamanca, Seminario Historia de la Medicina. El mismo problema se detecta, en SiERra VALENTí, X. (1994), "Giné y Partagás y los origenes de la dermatología en Catalunya», Acutalidad Dermatológica, 34, pp. 599-607.

26 Ausin Hervella, J.L. (2003), Dr. Giné i Partagás (1836-1903). En homenatge. Giné i Partagás, impulsor de la modernització de la medicina catalana, Barcelona, Collegi Oficial de Metges de Barcelona. El libro no tiene lugar de publicación ni ISBN. 
Su infancia y juventud se conocen gracias a su autobiografía, Mis maestros y mi educación, en la que, en un tono autocomplaciente, relata muchos avatares de su vida hasta $1848^{27}$. Como sucede en general en las autobiografías y las memorias, el autor intenta justificar y dar sentido a posteriori a sus acciones, desvirtuando o reinterpretando éstas. La proyección posterior de esta obra en sus biógrafos ha sido, como es lógico, enorme, si bien la utilización de los hechos y datos relatados por Rubio ha sido muy parcial e incluso se han obviado ciertas cuestiones que contradicen la imagen posteriormente creada sobre su persona, en especial su implicación política.

Por otra parte, la mayor parte de biografías y noticias sobre Rubio son de carácter hagiográfico y están vinculadas a distintas conmemoraciones y homenajes a su persona, especialmente a su muerte, lo que ha contribuido a mitificar su figura y transmitirnos una imagen poco humana de su persona. Inmediatamente después de su fallecimiento, en agosto de 1902, se organizaron diversos actos de homenaje a su figura en la que se ensalzaron sus cualidades como cirujano, maestro, creador de empresas científicas y pensador social. El tono hagiográfico de estos discursos y escritos es evidente y puede ser comprensible en el contexto emocional provocado por su fallecimiento. Sin embargo, la mitificación de Rubio, como ha señalado E. Bernal, había comenzado ya en 1900 en el marco de su bodas de oro con la profesión y su muerte no hizo más que profundizar la imagen que se había comenzado a crear $^{28}$. En los años siguientes esa imagen se consolidó y se acrecentó borrando su dimensión humana. En 1927, con motivo del centenario de su nacimiento, se repitieron los homenajes, marcados por la exaltación desmedida del cirujano. Desde entonces el grueso de los trabajos sobre su obra y figura han contribuido, a fuerza de ensalzarle, a crear una imagen de Rubio distorsionada, abstracta y ahistórica, que todavía hoy perdura.

Las biografías de Eugenio Gutierrez ${ }^{29}$, José Alvarez Sierra ${ }^{30}$ y Gabriel Sánchez Cuesta ${ }^{31}$, son los ejemplos más emblemáticos y acabados de esta tendencia.

27 Rubio y Gali, F. (1977), Mis maestros y mi educación, Madrid, Tebas.

28 BERnAL, E. (2003), «La construcción social de un mito: el caso de Federico Rubio». En: CARrillo Martos, J. L. (Ed) (2003), Medicina y sociedad en la España de la segunda mitad del siglo XIX: una aproximación a la obra de Federico Rubio y Gali. El Puerto de Santa María, Ayuntamiento de El Puerto de Santa Maria y Asociación para la Formación, Investigación y Asistencia médica en Andalucía «Federico Rubio», pp. 397-409

29 Gutierrez, E. (1903), Biografía del Excmo e Ilmo señor D. Federico Rubio y Gali, Madrid, Est. Tip de la viuda e Hijos de M. Tello.

30 Alvarez Sierra, J. (1947), El Dr. Federico Rubio. Vida y obra de un cirujano genial, Madrid, Editora Nacional.

31 SÁnchez De La Cuesta y Gutierrez, G. (1949), Ideario y grandeza de don Federico Rubio, Sevilla, Real Academia de Medicina de Sevilla. 
En las tres obras se combinan el relato de anécdotas de difícil comprobación, la exaltación desmesurada de su figura, la ocultación de datos, la ausencia de la más mínima crítica al protagonista y desde luego la inexistencia de una contextualización histórica que permita una valoración de sus aportaciones a la medicina española. Rubio es presentado en las tres como un personaje perfecto (buen maestro, buen cirujano, buena persona) que se convierte en una suerte de genio, de héroe solitario rodeado de meros comparsas, desapareciendo completamente el marco histórico en el que se desarrolló su vida. Una cuestión interesante son los intentos más o menos velados de negar o soslayar su faceta política y su pensamiento social. Su militancia liberal, democrática y republicana que le llevó a detentar diversos cargos electos entre 1869 y 1873 no es una cuestión en la que insistan especialmente sus biógrafos, que procuran despacharla, caso de hacerlo, en pocas palabras, tachándola como algo típico y tópico del turbulento siglo $\mathrm{XIX}^{32}$.

En cuanto al pensamiento social de Rubio, hasta fechas muy recientes, no había un abordaje serio que pretendiera contextualizarlo en su tiempo y conectarlo con el desarrollo de la medicina y de las políticas de reforma social que durante la Restauración comenzaban a atisbarse. Sus ideas sociales se presentaban por sus hagiógrafos como exclusivamente católicas o inspiradas en la caridad cristiana, lo que resulta chocante conociendo los fundamentos ideológicos de Rubio en lo político, económico y social. De hecho su primer biógrafo, Eugenio Gutierrez, que fue uno de sus más destacados discípulos, equipara, sin ningún tapujo, su pensamiento y obra social con la del Maestro, llegando a calificar algunos de su puntos de vista más propios de un santo que de un sociólogo. El único estudio que analizaba con seriedad su pensamiento socio-económico era el de Hernández Sandoica, que profundizaba, a la luz de su experiencia como empresario conservero y sus escritos sociales, en sus

32 Véase Alvarez Sierra (1947); SÁnchez Cuesta (1949). Sobre este aspecto llamó tempramente la atención HERNÁNDEZ SANDOICA, E. (1984), «Reforma social e iniciativa privada en un médico español del siglo XIX; Federico Rubio y Gali y su concepción de la sociedad» Asclepio, 36, pp. 325-346; véase también BERNAL (2003). Recientemente se ha emprendido el estudio de la militancia política de Rubio por parte de un grupo de historiadores de la Universidad de Sevilla, aportando nuevos datos sobre esta faceta .Todo ellos han sido publicados en CARRILlo MARTOS. (Ed) (2003), Véanse a este respecto: NuÑEZ GARCÍA, V.M; Calero Delgado, Ma L. (2003), «El papel político de Federico Rubio durante el bienio progresista (agosto-septiembre de 1854), pp. 315- 339; ARIAS CASTAÑón, E. (2003), «Federico Rubio y el republicanismo español», pp 341-378; MACARRO. J.M. (2003), «Federico Rubio, político y parlamentario: una manera de entender la revolución», pp. 379-387; SÁNCHEZ MANTERO, R. (2003), «Federico Rubio, embajador», pp. 389-396. 
propuestas mostrando la interacción entre teoría y práctica, asi como el rechazo del intervencionismo estatal en materia social que se daba en Rubio. Sus posiciones próximas a la asociación del capital, impregnadas de un profundo liberalismo económico y alejadas de las posturas que propugnaban el desarrollo de legislaciones sociales que favorecieran a la clase obrera, desde luego, poco tenían que ver con la postura oficial del catolicismo en esta materia ${ }^{33}$.

Como resultado de los actos conmemorativos del primer centenario del fallecimiento de Rubio y del 175 aniversario de su nacimiento (siempre los homenajes marcando la visión histórica del cirujano gaditano), ha visto la luz el libro Medicina y sociedad en la España de la segunda mitad del siglo XIX: una aproximación a la obra de Federico Rubio y Gali ${ }^{34}$. Al ser una obra de carácter colectivo el resultado es desigual. Hay algunos trabajos, los menos, que mantienen un estilo rancio y hagiográfico y que poco aportan a la visión de Rubio. Sin embargo, un número elevado de los estudios recogidos en él ahondan especialmente en los aspectos relacionados con su actividad política, pensamiento social, empresas científicas y tarea como cirujano con un tono y planteamientos metodológicos que ubican a Rubio en la realidad histórica de sus tiempo, abriendo el camino a un conocimiento más profundo de su figura.

La mitificación de Rubio ha sido, por tanto, el inconveniente más importante al emprender su biografía. Ha sido necesario contrastar la información «oficial» y las abiertas falsificaciones de la realidad vertidas por sus biógrafos con los testimonios del propio Rubio y de otros coetáneos, que sin negar su

33 Hernández SANDOICA (1984). El pensamiento social de Rubio quedó expuesto principalmente en: Rubio y Gali, F. (1890), La sociopatología. Discurso leido en la solemne sesión inagural del año de 1890 de la Real Academia de Medicina, Madrid, Est. Tip. E. Teodoro, pp. 25-49: DR. Ruderico (1894), La felicidad. Primeros ensayos de patología y de terapéutica social, Madrid, Est. Tip. E. Teodoro; : DR. RUDERICO (1902), La mujer gaditana. Apuntes de economía social, Madrid, Est. Tip. Idamor Moreno. El funcionamiento del Instituto Rubio, situado en Moncloa, debe mucho a su idea del capital asociado. CAMPOS MARÍN (2003), pp 97-107. En el mencionado libro editado por Juan Luis Carrillo en 2003, varios autores analizan su pensamiento social. Véanse: MonTIEL, L. (2003), «La otra cara de Federico Rubio», pp. 411-427; RuIZ GARCíA, C; GARCía DEL Moral, A. (2003), «Medicina, moral sexual y pedagogía en la obra de Federico Rubio: de la circuncisión», pp. 429-439; JIMÉNEZ LuCENA, I; RuIZ Somavilla, Ma J. (2003), «Discurso y práctica en Federico Rubio desde una perspectiva de género», pp. 441-452; CASTELlanOS, J. (2003), «La terapéutica social como'como ideal presente' en la obra de Federico Rubio», pp. 453-474.

34 CARrillo Martos, J. L. (Ed) (2003). Asociado a estas conmemoraciones se ha publicado también Carrillo, J.L; Bernal, E; Albarracín, A; Micó NaVarro, J.A; NuÑEz García, V.M. (2002), Federico Rubio y Gali (1827-1902): estudio documental y bibliográfico, Puerto de Santa María, Concejalía de Cultura del Ayuntamiento de El Puerto de Santa María. 
admiración por él, relatan algunos acontecimientos de manera bien distinta. Así es interesante subrayar que su primera ovariotomía no fue el éxito apuntado por sus biógrafos, ni que su pericia como anestesista fuera intachable ${ }^{35}$. Tampoco la creación del Instituto de Terapeútica Operatoria en las dependencias del Hospital de la Princesa fue fruto exclusivo de su generosidad, obstinación y clarividencia científica. Más bien fue el resultado de una mezcla de interés científico con ambiciones personales que provocó un profundo malestar entre los médicos del Hospital cuyo colofón fue el enfrentamiento abierto con el decano del mismo Carlos María Cortezo, decano del mismo. Este episodio, silenciado en la práctica totalidad de las biografías, sin embargo, es esencial para comprender la personalidad de Rubio pues ilustra como se desenvolvía entre sus colegas, ponía en marcha algunas de sus empresas científicas y como utilizaba las influencias políticas para lograr sus fines. Rubio no dudó en utlizar sus amistades en el gobierno y sacrificar a Cortezo en aras de sus objetivos personales ${ }^{36}$. La construcción de un edificio propio quince años después, en 1895, para albergar el Instituto Rubio también fue fruto de un trato de favor al ya entonces anciano cirujano. Diversas intervenciones de senadores como Pulido, del Alcalde de Madrid y de la Casa Real fueron decisivas tanto para recalificar los terrenos sobre los que se debía erigir como para obtener fondos para comenzar las obras ${ }^{37}$.

Este tipo de acontecimientos, celosamente obviados, contribuyen a dar una medida de Rubio mucho más sugerente que las acartonadas hagiografías, y no desmerecen sus méritos. No obstante, plantear estas cuestiones en una biografía divulgativa no es sencillo, pues se corre el riesgo de interrumpir con un exceso de consideraciones el acercamiento al personaje y su carácter sintético ${ }^{38}$.

35 El mismo Rubio desmiente esa imagen en su relato. RUBIO, F. (1863), «La primera ovariotomía en España», El Siglo Médico 10, pp. 687-690. Una reflexión interesante de la práctica de la ovariotomía por Rubio puede seguirse en JiMÉNEZ LUCENA; RUIZ SOMAVILLA (2003).

36 En este sentido, es muy esclarecedor el testimonio recogido en PULIDO, A. (1915), Mi aportación al Instituto Rubio. Cartas circunstanciales, Madrid, Imprenta de Enrique Teodoro. . Una interpretación muy interesante de la actitud de Rubio para conseguir crear el Instituto es la Porras Gallo, I. (2003), «Orígenes, fundación y evolución del Instituto de Terapéutica operatoria del Dr. Rubio en Madrid». En CARRILlo (Ed), pp. 269-286.

37 Pulido, A. (1897), El Instituto de Terapeútica Operatoria, fundado en la Moncloa por el Dr. Federico Rubio y Gali, Madrid, Establecimiento tipográfico de E. Teodoro .

38 El problema radica en la necesidad de exponer al lector la versión transmitida a lo largo del tiempo, aunque esté falseada y mostrarle al tiempo la versión más próxima a la que realmente aconteció. Este ejercicio no es sencillo en una biografía divulgativa. Sin embargo, dicho carácter o no debe servir como excusa para obviarlo. 
A la luz de lo expuesto, una futura biografía de Rubio debería afrontar a partir de un profundo trabajo de investigación de las fuentes disponibles y por descubrir, la dura tarea de combinar la presentación de su trayectoria con el estudio crítico de la producción de la memoria del médico andaluz transmitida por sus contempóraneos, indagando en los fines e interpretaciones de la misma. Tal vez así, podamos obtener una visión compleja y más completa que permita una reinterpretación de su figura y su importancia en la medicina española del siglo XIX. 